\title{
A family study of renal agenesis
}

\author{
C. O. CARTER, KATHLEEN EVANS, AND G. PESCIA ${ }^{1}$ \\ From the MRC Clinical Genetics Unit, Institute of Child Health, London WCIN 1EH
}

SUMMARY A family study of bilateral renal agenesis was undertaken based on 103 patients with bilateral renal agenesis, ascertained through stillbirth and neonatal death certificates, and confirmedi by necropsy reports; 28 were ascertained through paediatric pathologists. The families of 108 of these were traced and visited.

The birth frequency in the year in which ascertainment was likely to be most complete, 1974, was estimated to be $0 \cdot 12$ per 1000 total births, but it is recognised that this will be an underestimate. Nor significant variation was found by geographical region, parental birth place, socioeconomic class $s_{i}^{\omega}$ maternal age, or birth order. There was, however, an excess of conceptions in the spring quarters (March, April, and May), similar to, but in this series more marked than, that seen in neural tube? malformations.

The proportion of sibs affected was 7 in $199(3 \cdot 5 \%)$; of these, 6 were bilaterally and 1 was uni $\frac{c}{5}$ laterally (with an enlarged contralateral cystic kidney) affected. This is rather too high to be explainedb by multifactorial inheritance unless the estimate of the birth frequency is much too low. The pro $\vec{\vartheta}$ portion of sibs affected was similar for index patients with 'single' bilateral renal agenesis, with onlyet embryologically related malformations, and for index patients with associated malformations of unrelated bodily systems. Of the 199 sibs, 5 had neural tube malformations, but in 3 of these instances the index patient also had a neural tube malformation as well as renal agenesis. Where the index patient had ureteric remnants, 1 in 12 sibs were affected, but this high proportion may well just be aڤ chance effect.

Coincidence within families suggests that unilateral renal agenesis is genetically related to bilatera芦 renal agenesis, and that cases of bilateral renal agenesis without ureters are not genetically different from those with ureteric remnants.

Bilateral renal agenesis is a relatively common congenital malformation. Estimates of the frequency in British populations are of the order of $0 \cdot 1$ to $0 \cdot 2$ per 1000 births (Leck et al., 1968; Butler and Alberman, 1969). Most series show a marked male preponderance, with a male to female ratio of about $2 \cdot 5$ to 1 .

The first report of a family with two or more sibs affected was by Madisson (1934). By 1974 there were some 13 reports of individual families in which a patient with bilateral renal agenesis had a near relative with bilateral or unilateral renal agenesis. Two more recent reports, which quote the earlier references, are those of Pashayan et al. (1977) and Schinzel et al. (1978). However, no systematic family study has yet been made of the condition. The present study was designed to estimate the degree of familial aggregation for the condition, and to provide an

${ }^{1}$ Present address : Division Autonome de Génétique Medicale, Universitaire, Vaudois, Lausanne.

Received for publication 30 August 1978 empirical risk of recurrence in sibs. In the study, family information was also obtained for a smalis number of cases of unilateral renal agenesis; details 2 . are given, but the emphasis of the study is on bilaterab renal agenesis.

\section{Material and methods}

The main series of patients was ascertained with the kind help of the Office of Population Censuses and Surveys (OPCS). The details are shown in Table 1. 0 The first group of 16 index patients was obtained by N personal scrutiny (KAE) of all neonatal death ando stillbirth certificates for Greater London (1.4.65 too 31.3.68), which had been provided for another related research project. Those certificates where the primary or secondary cause of death was given aso renal agenesis, Potter's syndrome, or a not fully specified renal anomaly were extracted. For each child a necropsy report was sought and if this confirmed the presence of bilateral or unilateralo 176 
Table 1 Source of index patients. (From neonatal and stillbirth certificates (OPCS) and from 4 pathologists.)

\begin{tabular}{|c|c|c|c|c|c|c|}
\hline Grou & up & Bila & eral & Unil & ateral & Total \\
\hline & & & $F$ & $M$ & & \\
\hline (1) & Greater London (1.4.65 to & & & & & \\
\hline & Neonatal deaths & 6 & 1 & 3 & 1 & 11 \\
\hline & Stillbirths & 4 & 0 & 1 & 0 & 5 \\
\hline (2) & $\begin{array}{l}\text { Greater London (1.4.68 to } \\
31.12 .72 \text { ) }\end{array}$ & & & & & \\
\hline & Neonatal deaths (ICD 7530) & 9 & 1 & 1 & 1 & 12 \\
\hline & Stillbirths (ICD 530) & 2 & 3 & $\hat{1}$ & 0 & 6 \\
\hline (3) $]$ & England and Wales, 1973 & & & & & \\
\hline & Neonatal deaths (ICD 7530) & 14 & 3 & 4 & 3 & 24 \\
\hline & $\begin{array}{l}\text { From further analysis of } 25 \% \\
\text { due to 'multiple causes' }\end{array}$ & 8 & 2 & 2 & 0 & 12 \\
\hline (4) & England and Wales, 1974 & & & & & \\
\hline & Neonatal deaths (ICD 7530) & 30 & 4 & 1 & 3 & 38 \\
\hline & $\begin{array}{l}\text { From } 25 \% \text { due to 'multiple } \\
\text { causes' }\end{array}$ & 4 & 4 & 1 & 0 & 9 \\
\hline & Stillbirths (ICD 530) & 4 & 4 & 1 & 0 & 9 \\
\hline (5) & Pathologists' series & & & & & \\
\hline & Neonatal deaths & 13 & 5 & 0 & 0 & 18 \\
\hline & Stillbirths & 7 & 3 & 0 & 1 & 11 \\
\hline Tota & & 101 & 30 & 15 & 9 & 155 \\
\hline
\end{tabular}

renal agenesis the case was accepted as an index patient. The second group of 18 index patients was obtained from neonatal death and stillbirth certificates for Greater London (1.4.68 to 31.12.72), extracted by the staff of OPCS on the basis of the underlying cause of death (ICD 753.0, 8th Revision) entered in the computer-held death files. The third group of 36 was obtained from neonatal death certificates for England and Wales (1973). This group included 24 found by OPCS on the above criteria and another 12 cases from the further analysis of a $25 \%$ sample of all neonatal deaths for which all causes of death on the certificate had been coded and were therefore available to be searched in the computer-held files. The fourth group of 56 for England and Wales (1974) included 47 (38 and 9) ascertained from neonatal deaths as in group 3, and, in addition, 9 from stillbirth certificates. As in group 1, we sought a necropsy report for each case and the child was accepted as an index patient only if the presence of bilateral or unilateral renal agenesis was confirmed.

A fifth group of 29 cases was obtained through the kindness of 4 pathologists who had consecutive series of necropsy reports of neonatal deaths and stillbirths from bilateral renal agenesis (one unilateral case with hypoplasia of the other kidney was included). Any case from pathologists which had previously appeared in one of the first 4 groups was not used again.

Unilateral cases will be missed in a survey such as the present one, based on perinatal deaths, unless the single kidney is non-functional or there is some other cause of perinatal death.

The total series of index patients finally assembled was 131 (101 boys and 30 girls) with bilateral, and 24 ( 15 boys and 9 girls) with unilateral renal agenesis, 155 in all. These are shown in Appendix 1a and b. It is apparent that these cases do not include all children stillborn or dying neonatally from bilateral renal agenesis (still less unilateral renal agenesis) in the areas included between 1965 and 1974. For some perinatal deaths there is no necropsy. Where there is a necropsy the death certificate may have been completed before the findings were known and may give an imprecise cause of death, such as 'multiple anomalies', or may give an associated anomaly, for example, spina bifida, as the only cause of death. For example, in the course of the study, 6 of the families were found to have 2 affected sibs. In 3 of these families with a pair of affected sibs (see Appendix 1a no 37, 92, and 124), one sib was an index patient and the other was born outside the time or area surveyed. However, in 3 families both sibs might have been index patients and both sibs (no 35 and 112) were indeed ascertained independently in one family. In the other 2 families (no 25 and 110) the family was ascertained through only one patient. This was because the stillbirth certificate (in contrast to the necropsy report obtained after the family history was taken) of the affected sib did not give renal agenesis as a cause of death. Further, of a pair of concordant twins (no 28) only one was ascertained as an index patient, again because the stillbirth certificate of the other twin did not mention renal agenesis. The bias introduced by this incomplete ascertainment is likely to be that, except in the series supplied by the pathologists, the index patients will include relatively more of the cases with renal agenesis as a 'single' malformation (see below). This is apparent in Table 2 where, in bilateral cases, the proportions of 'single' malformations were 81 of $103(79 \%)$ in the series ascertained through OPCS, but 15 of $28(54 \%)$ in the series ascertained through the pathologists.

\section{CLASSIFICATION OF BILATERAL CASES}

A distinction may usefully be made between those patients in whom the malformation is 'single' or accompanied only by anomalies which are either secondary to, or probably embryologically related to, the main malformation, and those in whom it is 'multiple' with additional malformations of unrelated systems. In renal agenesis, malformations which may reasonably be regarded as secondary include Potter's facies, club foot, congenital dislocation of the hip, spade-like hands, and pulmonary hypoplasia. These are the result of oligohydramnios (P. Dunn, 1976, personal communication). Further, where there is an association of renal agenesis with abnormalities of the derivatives of the genital ducts, this may be 
regarded as the result of a similar, but more extensive, defect in embryogenesis. A somewhat more extensive defect would also affect the hindgut; a further extension still would affect the entire caudal end of the embryo (Buchta et al., 1973). All these have been included as part of the 'single' malformation.

In contrast, associations with neural tube, cardiac, facial cleft, tracheo-oesophageal, and eye defects probably represent unrelated malformations and so are of the second category, the 'multiple' malformation.

We have, therefore, divided the index patients into 2 main categories:

(1) Single. (Corresponding to 'single developmental field complex' of Buchta et al., 1973) including:

(a) Bilateral absence of kidneys with or without absence of ureters, uterus and/or vagina, ductus deferens, seminal vesicles.

(b) As above with, in addition, imperforate anus (usually with atresia of terminal hindgut), with or without morphological defects of the male external genitalia (hypoplasia of phallus, hypoplasia or absence of scrotum), or female external genitalia (hypertrophy of phallic tubercle with formation of male urethra).

(c) As above with, in addition, sirenomelia or absence of leg bones or sacral defects.

(2) Multiple. (Corresponding to 'multiple congenital anomaly' of Buchta et al., 1973) including:

As above with, in addition, heart, spinal (other than sacral), facial, tracheo-oesophageal, and other anomalies.

Table 2 shows the distribution of patients on this classification.

The details of the associated malformations in both the bilateral and unilateral category 2 patients are shown in Appendix 2. In all, 43 of the 155 patients $(28 \%)$ had such anomalies, which include defects of the heart (15), trachea and oesophagus (9), central nervous system (8), skull and face (6), eyes (7), and brain (4).

Potter (1965) has suggested that bilateral cases in which there is some element of ureter present are aetiologically distinct. We are not sure that this view is correct, but we have indicated in bilateral cases in Appendix 1a the 5 index patients who were recorded in the necropsy report as having had some elements of ureters, the 76 who were positively stated to have no ureters, and the 27 for whom the necropsy

Table 2 Allocation of all index patients to 'single' and 'multiple' categories distinguishing OPCS and pathologists' series

\begin{tabular}{llrrrrr}
\hline Category & \multirow{2}{*}{ Series } & \multicolumn{3}{c}{ Bilateral } & \multicolumn{3}{c}{ Unilateral } & Total \\
& & $M$ & $F$ & $M$ & $F$ & \\
\hline 1a & OPCS & 55 & 13 & 8 & 5 & 81 \\
& Pathology & 10 & 1 & 0 & 0 & 11 \\
1b & OPCS & 7 & 3 & 3 & 0 & 13 \\
& Pathology & 3 & 0 & 0 & 0 & 3 \\
1c & OPCS & 2 & 1 & 0 & 0 & 3 \\
& Pathology & 1 & 0 & 0 & 0 & 1 \\
Total & & 78 & 18 & 11 & 5 & 112 \\
2 & OPCS & 17 & 5 & 4 & 3 & 29 \\
& Pathology & 6 & 7 & 0 & 1 & 14 \\
Total & & 23 & 12 & 4 & 4 & 43 \\
Grand total & 101 & 30 & 15 & 9 & 155 \\
\hline
\end{tabular}

reports did not specify the presence or absence of ureters. A similar indication is given for the index! patients on whom we have no family informatio (Appendix 1b), and here 2 index patients haof elements of ureters, in 19 ureters were absent, and irs 2 the presence or absence of ureters was not specified

Of the 24 index patients with unilateral renaf agenesis, 17 had abnormalities of the other kidney other than simple enlargement. The comments, froms the necropsy reports, on the other kidney ares summarised in Appendix 2.

METHOD OF FAMILY STUDY

We set out to trace and take a family history of including sibs, parents, and first cousins, all 155parents of index patients, having first obtained the permission of the hospital consultant to include hispatient and of the family doctor to contact theor family. No family information was obtained for 23 ? of the 131 bilateral cases. The reasons were: not traced, 15; unwilling to help, 5; the physicians involved considered it inadvisable for us to contact families, 3 . Of the 24 unilateral cases, we were not able to trace the families of 6 . Thus, the familyco information is based on 108 bilateral and 18 unilateral index patients.

With the exception of $\mathbf{3}$ families, where the familys doctors preferred to collect and give us the informa-o tion themselves, all families were visited in theiro homes. At the visit, a family and pregnancy history was taken. Any report of stillbirth, death, or surviva $\vec{F}$ with an abnormality in a sib was verified from 3 medical records. For parents and first cousins? medical records were sought only if there was $\mathrm{a}$. history suggestive of renal anomaly or congenital malformation. Relatives were scored as affectedo only when the diagnosis of renal agenesis waso confirmed at necropsy.

\section{BIRTH FREQUENCY}

In the present survey for 1974 , the year in which ascertainment was most extensive, we were able to $>$ confirm 50 cases of bilateral renal agenesis from necropsy reports. In 42 of these, renal agenesis wasn mentioned on the death or stillbirth certificate and the remaining 8 cases were from the $25 \%$ of deathso from multiple causes which were further analysed. $\tilde{\omega}$ This suggests a total for the year of 74. In addition it is reasonable to include 4 instances where noo necropsy report was available, but where the death certificate mentioned bilateral renal agenesis, and ${ }^{\infty}$ we have scored 2 death certificates labelled 'Potter's 0 syndrome' where no necropsy reports were available as one further case. Thus, the estimate for the yearo is 79 cases in 647060 total births, that is 0.122 per⿳亠口冋 1000 total births. 
SEASON OF BIRTH AND CONCEPTION

A comparison of the observed with the expected distribution from the Registrar General's tables (Birth Statistics, OPCS 1974, Table 2.4, and Statistical Review, 1973, TT) by season of birth for bilateral cases is shown in Table 3a. Those born in 1973 and 1974 are compared with England and Wales and those born 1965 to 1972 with Greater London (Greater London, 1968, unpublished data).

The distribution by season of conception is of more interest. The estimated length of gestation found in the records of 81 index patients and 8 further patients recorded as 'premature' were assumed to have had a gestation of 36 weeks. The distribution (taking the date of the start of the last menstrual period as the date of conception) is shown in Table $3 \mathrm{~b}$ and compared with that of the corresponding England and Wales population, assuming 9 months' gestation.

MATERNAL AGE AND BIRTH ORDER

Using index patients with bilateral renal agenesis

Table 3a Observed and expected bilateral renal agenesis births by month of occurrence

\begin{tabular}{|c|c|c|c|c|c|c|c|}
\hline & \multicolumn{2}{|c|}{$\begin{array}{l}\text { England and } \\
\text { Wales } \\
1973-1974\end{array}$} & \multicolumn{2}{|c|}{$\begin{array}{l}\text { Greater } \\
\text { London } \\
1965-1972\end{array}$} & \multicolumn{2}{|l|}{ Total } & \multirow[t]{2}{*}{$O b s / E x p$} \\
\hline & $O$ & $E$ & $O$ & $E$ & $O$ & $E$ & \\
\hline January & 11 & $6 \cdot 62$ & 4 & $2 \cdot 18$ & 15 & $8 \cdot 80$ & $1 \cdot 70$ \\
\hline February & 5 & 6.03 & 5 & $2 \cdot 14$ & 10 & $8 \cdot 17$ & $1 \cdot 22$ \\
\hline March & 9 & $7 \cdot 04$ & 1 & $2 \cdot 39$ & 10 & 9.43 & $1 \cdot 06$ \\
\hline April & 6 & $6 \cdot 47$ & 0 & $2 \cdot 22$ & 6 & $8 \cdot 69$ & 0.69 \\
\hline May & 6 & $6 \cdot 81$ & 2 & $2 \cdot 30$ & 8 & $9 \cdot 11$ & 0.88 \\
\hline June & 5 & $6 \cdot 41$ & 0 & $2 \cdot 18$ & 5 & $8 \cdot 59$ & 0.58 \\
\hline July & 5 & 6.65 & 2 & $2 \cdot 26$ & 7 & $8 \cdot 91$ & 0.79 \\
\hline August & 2 & $6 \cdot 49$ & 5 & $2 \cdot 21$ & 7 & $8 \cdot 70$ & 0.80 \\
\hline September & 5 & $6 \cdot 31$ & 1 & $2 \cdot 05$ & 6 & $8 \cdot 36$ & 0.72 \\
\hline October & 7 & $6 \cdot 34$ & 2 & $2 \cdot 05$ & 9 & $8 \cdot 39$ & 1.07 \\
\hline November & 7 & $5 \cdot 87$ & 0 & $1 \cdot 96$ & 7 & $7 \cdot 83$ & 0.89 \\
\hline December & 9 & $5 \cdot 94$ & 4 & $2 \cdot 04$ & 13 & $7 \cdot 98$ & $1 \cdot 63$ \\
\hline Total & 77 & 77 & 26 & 26 & 103 & 103 & \\
\hline
\end{tabular}

Pathologists' cases are not included.

Table 3b Observed and expected bilateral renal agenesis births by estimated month of conception

\begin{tabular}{|c|c|c|c|c|c|c|c|}
\hline & \multicolumn{2}{|c|}{$\begin{array}{l}\text { England and } \\
\text { Wales } \\
1973-1974\end{array}$} & \multicolumn{2}{|c|}{$\begin{array}{l}\text { Greater } \\
\text { London } \\
1965-1972\end{array}$} & \multicolumn{2}{|c|}{ Total } & \multirow[t]{2}{*}{ Obs/Exp } \\
\hline & $O$ & $E$ & $O$ & $E$ & $O$ & $E$ & \\
\hline January & 1 & $5 \cdot 44$ & 2 & $1 \cdot 86$ & 3 & $7 \cdot 31$ & 0.41 \\
\hline February & 6 & $5 \cdot 03$ & 0 & $1 \cdot 76$ & 6 & $6 \cdot 79$ & 0.88 \\
\hline March & 6 & $5 \cdot 09$ & 2 & $1 \cdot 83$ & 8 & $6 \cdot 92$ & $1 \cdot 16$ \\
\hline April & 11 & $5 \cdot 68$ & 3 & $1 \cdot 94$ & 14 & $7 \cdot 62$ & $1 \cdot 84$ \\
\hline May & 7 & $5 \cdot 17$ & 4 & $1 \cdot 88$ & 11 & $7 \cdot 05$ & $1 \cdot 56$ \\
\hline June & 4 & $6 \cdot 03$ & 4 & $2 \cdot 10$ & 8 & $8 \cdot 13$ & 0.98 \\
\hline July & 9 & $5 \cdot 55$ & 0 & $1 \cdot 95$ & 9 & $7 \cdot 50$ & $1 \cdot 20$ \\
\hline August & 6 & $5 \cdot 84$ & 1 & $2 \cdot 03$ & 7 & $7 \cdot 87$ & 0.89 \\
\hline September & 4 & $5 \cdot 49$ & 1 & $1 \cdot 91$ & 5 & $7 \cdot 40$ & 0.68 \\
\hline October & 3 & $5 \cdot 70$ & 1 & $1 \cdot 95$ & 4 & $7 \cdot 65$ & 0.52 \\
\hline November & 4 & $5 \cdot 56$ & 4 & $1 \cdot 94$ & 8 & $7 \cdot 50$ & 1.07 \\
\hline December & 5 & $5 \cdot 42$ & 1 & $1 \cdot 85$ & 6 & $7 \cdot 27$ & 0.83 \\
\hline Total & 66 & 66 & 23 & 23 & 89 & 89 & \\
\hline
\end{tabular}

Pathologists' cases not included.
Table 4a Distribution by maternal age and no of previous live born sibs of index patients (bilateral) compared with expected for those born 1973-1974

\begin{tabular}{|c|c|c|c|c|c|c|c|c|c|c|}
\hline \multirow{2}{*}{$\begin{array}{l}\text { Maternal } \\
\text { age }\end{array}$} & \multicolumn{10}{|c|}{ No of previous children } \\
\hline & $\begin{array}{l}O \\
O\end{array}$ & $E$ & $\begin{array}{l}l \\
O\end{array}$ & $E$ & $\begin{array}{l}2 \\
O\end{array}$ & $E$ & $\begin{array}{l}3+ \\
O\end{array}$ & $E$ & $\begin{array}{l}\text { Tot } \\
O\end{array}$ & $\stackrel{a l}{E}$ \\
\hline $15-19$ & 7 & $4 \cdot 87$ & 2 & $1 \cdot 10$ & 0 & 0.08 & 0 & 0.00 & 9 & 6.05 \\
\hline $20-24$ & 11 & $12 \cdot 34$ & 3 & $8 \cdot 74$ & 5 & $2 \cdot 05$ & 1 & $0 \cdot 52$ & 20 & $23 \cdot 65$ \\
\hline $25-29$ & 9 & $9 \cdot 80$ & 11 & $11 \cdot 51$ & 5 & $3 \cdot 86$ & 3 & $1 \cdot 64$ & 28 & $26 \cdot 81$ \\
\hline $30-34$ & 3 & $2 \cdot 01$ & 4 & $3 \cdot 55$ & 1 & $2 \cdot 28$ & 1 & $1 \cdot 69$ & 9 & $9 \cdot 53$ \\
\hline $35+$ & 0 & 0.58 & 1 & 0.91 & 2 & 0.90 & 1 & $1 \cdot 57$ & 4 & 3.96 \\
\hline Total & 30 & $29 \cdot 60$ & 21 & $25 \cdot 81$ & 13 & $9 \cdot 17$ & 6 & $5 \cdot 42$ & 70 & $70 \cdot 00$ \\
\hline
\end{tabular}

Table 4b Birth order standardised for maternal age

No of children born before index patient

\begin{tabular}{lllllllll}
\hline$O$ & & 1 & & 2 & & $3+$ & & Total \\
$O$ & $E$ & $O$ & $E$ & $O$ & $E$ & $O$ & $E$ & \\
\hline 30 & 30.41 & 21 & 25.37 & 13 & 8.92 & 6 & 5.30 & 70
\end{tabular}

Table 4c Maternal age standardised for birth order

Mother's age at birth of index patient

\begin{tabular}{llllll}
\hline $15-19$ & $20-24$ & $25-29$ & $30-34$ & $35+\ldots$ & Total
\end{tabular}

\begin{tabular}{lllllllllll}
$O$ & $E$ & $O$ & $E$ & $O$ & $E$ & $O$ & $E$ & $O$ & $E$ & \\
\hline 9 & 5.94 & 20 & 23.07 & 28 & 26.60 & 9 & 10.05 & 4 & 4.34 & 70
\end{tabular}

born in 1973 and 1974, the two years when ascertainment was most complete and included the whole of England and Wales, a comparison with the expected distribution is shown in Table 4a (Birth Statistics, OPCS, 1974).

Table 4b shows birth order standardised for maternal age and Table $4 \mathrm{c}$ shows maternal age standardised for birth order.

\section{OTHER EPIDEMIOLOGICAL ASPECTS}

The distribution of cases by place of birth (Hospital Region), parental birth place, and socioeconomic class of fathers was also examined. No significant variation was found.

FAMILY DATA

The family data collected at interview are summarised in Appendix 1a, where each index patient is shown together with his date of birth, weeks of gestation, category of renal agenesis, presence or absence of ureters, sibs (showing those affected), and parents. The index patients whose parents were not seen are listed separately in Appendix 1b.

\section{SEX RATIO}

The sex ratio was $3 \cdot 37$ in the bilateral group, 1.67 in the unilateral group, and 2.97 in the two groups combined.

PARENTAL CONSANG UINITY

One patient (no 46) had parents who were first cousins once removed, and one (no 69) had parents who were third cousins. 
TWINS

There were 5 twin-born index patients (no 15, 28, 75,79 , and 96). All were males, as were all the cotwins. Index patient no 15 (category 2 with atrial and ventricular septal defect) had a normal twin brother, zygosity not known. Index patient no 28 (category $1 \mathrm{~b}$ with rectal agenesis) had a stillborn twin with a single midline kidney and ureter, a single midline testis at the lower pole of the kidney, micropenis, exstrophy of the bladder, exomphalos, absent colon and rectum with a short ileum opening directly into the bladder, and a closed sacral meningomyelocele with incomplete dorsoventral reduplication of the cord. The afterbirth was recorded as monochorionic. The second twin was not ascertained as an index patient. Index patient no 75 (category $1 \mathrm{~b}$ with absent penis) had a normal twin brother; the afterbirth was recorded as monoamniotic and monochorionic. Index patient no 79 (category 2 with tracheo-oesophageal fistula) had a normal twin brother; they were said to be uniovular on the death certificate. Index patient no 96 (category 1a) had a twin brother with talipes and the type of twinning was not known.

In summary, 5 male index patients had male cotwins. Of 3 probably monozygotic co-twins, one had a form of unilateral renal agenesis and 2 were unaffected, and of 2 co-twins of unknown type both were unaffected.

\section{SIBS}

The information on sibs is summarised in Table 5a.

Four of $92(4 \cdot 34 \%)$ brothers and 3 of $107(2 \cdot 80 \%)$ sisters had renal agenesis. That is 7 of $199(3.52 \%)$ of sibs combining both sexes. For male index patients the proportions were 2 in 70 brothers an $\$$ 2 in 86 sisters, that is 4 in $156(2.56 \%)$, and for female index patients the proportions were 2 in 2 brothers and 1 in 21 sisters, that is 3 in $43(6.98 \%) \frac{\text { क }}{4}$ One further sister of a girl (no 123) was stillboris and might have been affected; there was no necropsy but the father thought the facies were similar to those of the index patient. For category 1 patients 4 in 68 brothers and 1 in 73 sisters, that is 5 in $14 \mathrm{ks}$ $(3.55 \%)$ were affected. For category 2 patients, the proportions were 0 in 24 brothers and 2 in 34 sisters that is 2 in $58(3.45 \%)$.

Table $5 \mathrm{~b}$ shows the proportion of sibs affected when the sibs are distinguished by the presence ob absence of ureteric remnants.

The category of the affected sibs in relation to that of the index patients is shown in Table 6. It should benoted that patient no 35 and 112 are the affected sib pair who were both index patients. In only one? case (no 92) was the sib affected unilaterally (theother kidney was enlarged and cystic).

Details of the malformations in sibs (who had nक्ठ renal tract malformation) are shown in Table 7. The malformations were: 5 of the neural tube, 2 of the heart, and 1 of the trachea/oesophagus.

UNILATERAL INDEX PATIENTS

The number of sibs is shown in Table 8; none waso affected with renalagenesis, but one brother(of patiento no 152) was stillborn with myocardial hypertrophy\&

PARENTS

Inquiries were made about any history of rena illness in parents. Only one parent, a father, had significant history; he had hypertension, was in

Table 5a Sibs of 108 patients with bilateral renal agenesis distinguished by category (see text). (No of affected shown in brackets)

\begin{tabular}{|c|c|c|c|c|c|c|c|c|c|}
\hline \multirow[t]{2}{*}{ Category } & \multicolumn{4}{|c|}{ Male index patients } & \multicolumn{4}{|c|}{ Female index patients } & \multirow[t]{2}{*}{ Total sibs } \\
\hline & No & Brothers & Sisters & Total & No & Brothers & Sisters & Total & \\
\hline $\begin{array}{l}\text { 1a } \\
1 \mathrm{~b} \\
1 \mathrm{c} \\
\text { Total } \\
2 \\
\text { Total } 1+2\end{array}$ & $\begin{array}{r}52 \\
9 \\
2 \\
63 \\
19 \\
82\end{array}$ & $\begin{array}{c}43(2) \\
7 \\
3 \\
53(2) \\
17 \\
70(2)\end{array}$ & $\begin{array}{c}52 \\
8(1) \\
2 \\
62(1) \\
24(1) \\
86(2)\end{array}$ & $\begin{array}{r}95(2) \\
15(1) \\
5 \\
115(3) \\
41(1) \\
156(4)\end{array}$ & $\begin{array}{r}13 \\
2 \\
1 \\
16 \\
10 \\
26\end{array}$ & $\begin{array}{c}13(2) \\
1 \\
1 \\
15(2) \\
7 \\
22(2)\end{array}$ & $\begin{array}{l}9 \\
1 \\
1 \\
11 \\
10(1) \\
21(1)\end{array}$ & $\begin{array}{l}22(2) \\
2 \\
2 \\
26(2) \\
17(1) \\
43(3)\end{array}$ & $\begin{array}{r}117(4) \\
17(1) \\
7 \\
141(5) \\
58(2) \\
199(7)\end{array}$ \\
\hline
\end{tabular}

Table 5b Sibs of 108 patients with bilateral renal agenesis distinguished by presence or absence of ureteric remnants (see text) (No of affected shown in brackets)

\begin{tabular}{|c|c|c|c|c|c|c|c|c|c|}
\hline \multirow[t]{2}{*}{ Ureters } & \multicolumn{4}{|c|}{ Male index patients } & \multicolumn{4}{|c|}{ Female index patients } & \multirow[t]{2}{*}{ Total sibs } \\
\hline & No & Brothers & Sisters & Total & No & Brothers & Sisters & Total & \\
\hline $\begin{array}{l}\text { Remnants present } \\
\quad(\mathrm{tt}) \\
\text { Absent (a) } \\
\text { Not specified (ns) } \\
\text { Total }\end{array}$ & $\begin{array}{r}3 \\
55 \\
24 \\
82 \\
\end{array}$ & $\begin{array}{l}3 \\
44(2) \\
23 \\
70(2)\end{array}$ & $\begin{array}{c}6 \\
51(1) \\
29(1) \\
86(2)\end{array}$ & $\begin{array}{r}9 \\
95(3) \\
52(1) \\
156(4)\end{array}$ & $\begin{array}{r}2 \\
21 \\
3 \\
26\end{array}$ & $\begin{array}{c}0 \\
18(2) \\
4 \\
22(2)\end{array}$ & $\begin{array}{r}3(1) \\
17 \\
1 \\
21(1) \\
\end{array}$ & $\begin{array}{r}3(1) \\
35(2) \\
5 \\
43(3)\end{array}$ & $\begin{array}{r}12(1) \\
130(5) \\
57(1) \\
199(7) \\
\end{array}$ \\
\hline
\end{tabular}


Table 6 Index patients (all bilateral) with an affected sib showing category of anomaly in both index patient and sib

\begin{tabular}{|c|c|c|c|c|}
\hline \multicolumn{4}{|c|}{ Index patient } & \\
\hline 37 & Ma & $1 \mathbf{a}$ & $1 \mathrm{a}$ & Ma, bilateral, died 2 hours \\
\hline 92 & $\mathbf{M a}$ & $1 \mathrm{a}$ & 1a & $\begin{array}{l}\text { M, unilateral (other kidney enlarged and } \\
\text { cystic), died } 2 \text { hours }\end{array}$ \\
\hline 110 & $\mathbf{F a}$ & $1 \mathbf{a}$ & $1 \mathrm{a}$ & Ma, bilateral, stillborn \\
\hline 112 & $\mathbf{F a}$ & la & $1 \mathrm{~b}$ & Ma, bilateral, died 1 hour (no 35) \\
\hline 35 & Ma & $1 \mathrm{~b}$ & 1a & Fa, bilateral, died 1 hour (no 112) \\
\hline 25 & Mns & 2 & 2 & Fns, bilateral (atresia larynx, syndactyly), \\
\hline (one & eye at & sent) & & stillborn \\
\hline 124 & $\begin{array}{l}\mathrm{Ftt} \\
\mathrm{hel}\end{array}$ & $\begin{array}{l}2 \\
\text { enosi }\end{array}$ & 1a & Fns, bilateral, stillborn \\
\hline
\end{tabular}

a, ureters stated to be absent; $t$, ureteric elements present bilaterally; ns, no statement on ureter.

Table 7 Malformations in sibs, with no renal tract malformations, of bilateral index patients

\begin{tabular}{|c|c|c|c|c|}
\hline \multicolumn{3}{|c|}{ Index patient (bilateral) } & $\begin{array}{l}\text { Sib } \\
\text { Sex }\end{array}$ & Malformation \\
\hline 19 & $\mathbf{M}$ & $1 \mathrm{a}$ & $\mathbf{F}$ & tracheo-oesophageal atresia (alive) \\
\hline 54 & $\mathbf{M}$ & $1 \mathrm{a}$ & $\mathbf{F}$ & $\begin{array}{l}\text { ventricular septal defect (died } 5 \mathrm{~m} \text {, } \\
\text { no necropsy) }\end{array}$ \\
\hline 90 & $\mathbf{M}$ & $1 \mathrm{a}$ & $\mathbf{F}$ & meningocele (alive) \\
\hline 97 & $\mathbf{M}$ & $1 a$ & $\mathbf{F}$ & anencephaly (stillborn, no necropsy) \\
\hline 110 & $\mathbf{M}$ & $1 \mathrm{a}$ & $\mathbf{F}$ & persistent ductus arteriosus (alive) \\
\hline 26 & $\begin{array}{l}\mathbf{M} \\
\text { spina }\end{array}$ & $\begin{array}{l}2 \\
\text { bifida }\end{array}$ & $\mathbf{F}$ & meningocele (died $3 \mathrm{~m}$, no necropsy) \\
\hline 85 & catar & 2 & $\mathbf{M}$ & spina bifida (died $3 \mathrm{~d}$, no necropsy) \\
\hline 125 & $\begin{array}{l}\mathbf{F} \\
\text { spina }\end{array}$ & $\stackrel{2}{\text { bifida }}$ & $\mathbf{M}$ & spina bifida (alive) \\
\hline
\end{tabular}

renal failure, and on haemodialysis. An intravenous urogram had shown bilateral, small, smooth kidneys. It is of interest that 2 (no 35 and 112) of his 3 children were affected. One mother (of patient no 108) had spinal dysraphism with spina bifida occulta of the first sacral vertebra, deviation of the spine to the left at the lumbosacral joint with a naevus over the lower lumbar spine, and one leg and foot shorter and thinner than the other.

\section{COUSINS}

The bilateral index patients had 705 first cousins. None was found to have renal agenesis. The other malformations recorded in cousins include: one (of patient no 60) dying neonatally with bilateral severely hypoplastic kidneys (index patient had bilateral renal agenesis, but ureteric buds were present) and 6 instances of neural tube malformations.

The unilateral index patients had 151 first cousins. None was found to have renal agenesis, but 2 had a neural tube malformation.

\section{Discussion \\ EPIDEMIOLOGICAL CONSIDERATIONS}

\section{Birth frequency}

The estimate for bilateral cases in this survey, $0 \cdot 12$ per 1000 total births for the year 1974, is close to that of the 1958 Perinatal Mortality Survey (Butler and Alberman, 1969); they found 27 in 208872 total births $(0 \cdot 13$ per 1000$)$. In the large Birmingham survey (Leck et al., 1968), the birth frequency was a little higher; there were 35 bilateral cases among 190236 total births $(0 \cdot 18$ per 1000). All 3 series will have missed cases in which there was no necropsy. However, in the Butler and Alberman (1969) survey, a determined attempt was made to arrange necropsies on all perinatal deaths, and in the second half of the Birmingham survey, two-thirds of stillbirths and four-fifths of deaths in the first fortnight underwent necropsy.

Estimates of birth frequency of unilateral cases will not include those with normal contralateral kidneys and these will be the majority. In the present survey, based on stillbirth and death certificates, there were, in 1974, only 6 unilateral compared with 50 bilateral cases. In the Birmingham survey (Leck et al., 1968), with a follow-up to 5 years and inclusion of surviving children, there were 25 unilateral compared with 35 bilateral cases. In the Perinatal Mortality Survey (Butler and Alberman, 1969), there were 28 unilateral compared with 27 bilateral cases. The low figure in the present series is understandable, since unilateral renal agenesis would not be the main cause of a perinatal death.

\section{Seasonal variation}

There is an excess in the proportion of births with bilateral renal agenesis in the winter months of October to March with a peak in December,

Table 8 Sibs of 18 patients with unilateral renal agenesis

\begin{tabular}{|c|c|c|c|c|c|c|c|c|c|}
\hline \multirow[t]{2}{*}{ Category } & \multicolumn{4}{|c|}{ Male index patients } & \multicolumn{4}{|c|}{ Female index patients } & \multirow{2}{*}{$\begin{array}{l}\text { Total sibs } \\
\text { male and } \\
\text { female }\end{array}$} \\
\hline & No & Brothers & Sisters & Total & No & Brothers & Sisters & Total & \\
\hline $1 \mathbf{a}$ & 5 & 5 & 5 & 10 & 4 & 4 & 3 & 7 & 17 \\
\hline $1 \mathrm{~b}$ & 2 & 3 & 3 & 6 & $\mathbf{0}$ & 0 & 0 & $\mathbf{0}$ & 6 \\
\hline $1 \mathrm{c}$ & $\mathbf{0}$ & $\mathbf{0}$ & 0 & 0 & 0 & 0 & 0 & 0 & 0 \\
\hline Total & 7 & 8 & 8 & 16 & 4 & 4 & 3 & 7 & 23 \\
\hline 2 & 4 & 1 & 5 & 6 & 3 & 1 & 1 & 2 & 8 \\
\hline Total $1+2$ & 11 & 9 & 13 & 22 & 7 & 5 & 4 & 9 & 31 \\
\hline
\end{tabular}


January, and February. There is a similar excess proportion of conceptions (taking the first day of the last menstrual period as the date of conception) in the 6 months from March to August with a peak in March, April, and May. These swings are consistent in both the 1973 to 1974 and 1965 to 1972 series. It is interesting that the seasonal differences are similar to those that have long been observed for neural tube malformations. For example, for anencephaly in England and Wales the peak for conceptions (again taking the first day of the last menstrual period as the start) is February, March, and April and for spina bifida cystica is April, May, and June (Rogers and Weatherall, 1976). Thus, the peak of conceptions for renal agenesis falls between the peaks for anencephaly and spina bifida. In this series, the seasonal variation is more marked for bilateral renal agenesis than for the neural tube malformations. However, we had no prior hypothesis for the direction of any seasonal variation and it is desirable now to check this finding on a second series.

\section{Maternal age and birth order}

There is no indication of any effect of maternal age or birth order.

\section{GENETIC CONSIDERATIONS}

\section{Relationship between bilateral and unilateral renal agenesis}

Although Potter $(1965,1972)$ has suggested that, to some degree at least, the aetiology of unilateral and bilateral cases of renal agenesis differs, there is no doubt that in some instances there is a genetic relationship between the two. In our series, there was a pair of monozygotic twins (no 28), one with bilateral and one with unilateral renal agenesis. A similar twin pair has been reported by Mauer et al. (1974). In the present study, one bilaterally affected index case (no 92) had a sib with an absent right kidney and enlarged cystic left kidney, and further instances of bilateral cases with a sib with unilateral renal agenesis have been reported, for example, Winter et al. (1968), Cain et al. (1974). Further, Kohn and Borns (1973) reported a bilaterally affected index patient whose father's intravenous urogram showed only one kidney. We have recently arranged for the examination of a sample of parents and sibs of index patients for renal anomalies by ultrasonography. The findings will be reported later. Already one instance of unilateral renal agenesis, and one of unilateral renal hypoplasia, have been found in parents of patients with bilateral renal agenesis.

Further, it is clear that it is not the bilateral cases which have ureteric remnants that are related to unilateral cases (see next section).

\section{Relationship between cases with and without} elements of ureters

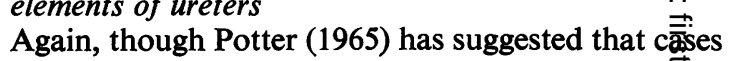
with some element of ureteric development differ from those with complete absence of ureters, thee is evidence of a genetic relationship, since the forms occur together within sibships. For examgle, in the family of Hack et al. (1974), one patient flad no ureters, but his sib had ureteric buds an\& a nodule of renal tissue on one side. In family Buchta et al. (1973), one sib had no ureters, but $\overrightarrow{\text { One }}$ other probably had rudimentary ureters. Of thf 5 bilateral index patients in the present study whofire specifically reported to have had some element? of ureters (no 58,60,69,120, and 124), one (no \$4) had a bilaterally affected sib, but the presenceivor absence of ureters was not stated in the necropssy report on the sib.

There is no indication that it is only the bilateral cases with ureteric remnants that are related to the unilateral cases. In this series, the index patient no 28) who had a monozygotic twin with unilateral renal agenesis also had no ureters. The index pationt (no 92) who had a unilaterally affected sib hadcho ureters. This was also true of the family reported by Cain et al. (1974). In family D of Buchta et al. (19\$3), a woman with unilateral renal agenesis had Exvo daughters with unilateral renal agenesis, a son no right kidney and only a pea-sized nodule on $\mathrm{C}^{\mathrm{T}} \mathrm{he}$ left, but bilateral ureters, and a niece with 'complete renal agenesis'. In the family of Kohn and Bơrns (1973), the bilaterally affected index patient with a unilaterally affected father had no ureters.

\section{GENETIC MECHANISMS}

No clear conclusions on the type of inheritance gan be made from the data at present available.

The twins, with one of the three monozygoticicotwins partially concordant, contribute little except to show that a monozygotic co-twin of a bilateral case need not also have renal agenesis, and that there is a genetic relationship between bilateral unilateral cases. Mauer et al. (1974) also reporte a monozygotic co-twin of a bilateral case who thad unilateral agenesis. Davidson and Ross (1954), surveying published reports at that date, foun\& 6 reports of cases who were twin-born and in all the
co-twin was unaffected.

The overall findings in sibs of the bilateral infex patients, 7 in $199(3.5 \%)$ affected, is, if truly representative, too high a proportion to be compatible with simple additive polygenic inheritance, if the birth frequency really is of the order of $0.0150 \mathrm{D} \%$, since a heritability of well over $100 \%$ is implied. Fut the figure of $3.5 \%$ is based on only 7 subjects and has a standard error of $1 \cdot 3 \%$. 
It may be that the material is genetically heterogeneous and includes recessive and dominantly inherited cases. There is, however, no direct evidence of this from the study except that one category 2 index patient (no 25) may be an example of a known recessive syndrome (see below). There is no excess of parental consanguinity in this series (one first cousin once removed and one third cousin marriage) and no instance of 3 sibs affected. Buchta et al. (1973) suggested that, while bilateral primary agenesis without ureters might be polygenically inherited, the unilateral and bilateral cases with ureteric remnants, which they called 'hereditary renal adysplasia', might be dominantly inherited. We have not found clear cut support for this hypothesis in this series, but nor are we able to contradict it except to note, as mentioned above, that both types of agenesis may occur in the same family.

With respect to the categories of bilaterally affected index patients, the proportion of sibs affected is similar; for category 1 and 2 index patients, 5 in 141 $(3.5 \%)$, and 2 in $58(3.4 \%)$, respectively. For index patients without ureters the proportion is 5 in 130 $(3.8 \%)$, for those where the presence or absence of ureters was not specified it is 1 in $57(1.8 \%)$, and for those with ureteric remnants it is 1 in $12(8 \cdot 3 \%)$. The apparently high proportion, 1 in 12 , for the last group is, perhaps, simply a chance effect because of small numbers.

Case no 25 and his sister may be examples of the variable and somewhat ill-defined, probably recessive, cryptophthalmos syndrome, the main features of which are cryptophthalmos, auditory atresia, syndactyly, and genital anomalies, with renal agenesis and laryngeal atresia as less common features (Francois, 1969). Case no 25 had unilateral cryptophthalmos, his sister syndactyly and laryngeal atresia, in addition to renal agenesis. If this pair were excluded, the remaining 29 category 2 index patients had only 1 sib affected in 55 .

There is no strong indication in this series of any familial relationship of renal agenesis with congenital malformations of other systems. It is noteworthy that 5 of 199 sibs had a neural tube malformation (without renal agenesis), where the expected proportion (taking 5 in 1000 as the incidence in the general population for neural tube malformations over the same period) would be only one. However, in 3 of the 5 cases the index patient was in category 2, and 2 (no 26 and 125) also had spina bifida. Among the 705 cousins of the bilateral index patients, 6 had neural tube malformation when 3.5 would be expected; in one instance the index patient (no 103) also had spina bifida and in another (no 27) tracheo-oesophageal fistula.

The recurrence risk suggested by this series is an indication for prenatal screening by ultrasound in subsequent pregnancies.

We are most grateful to $\mathrm{Dr} J$. Weatherall and the staff of OPCS who kindly supplied the neonatal death and stillbirth certificates; to the very many hospital consultants who sent details about their patients and allowed us to include them in the study; to the family doctors who helped us make contact with the parents; and to Miss R. Coffey who helped with the family visiting.

\section{References}

Buchta, R. M., Viseskul, C., Gilbert, E. F., Sarto, G. E., and Opitz, J. M. (1973). Familial bilateral renal agenesis and hereditary renal adysplasia. Zeitschrift für Kinderheilkunde, 115, 111-129.

Butler, N., and Alberman, E. (1969). Perinatal Problems. The Second Report of the British Perinatal Mortality Survey. Livingstone, London.

Cain, D. R., Griggs, D., Lackey, D. A., and Kagan, B. M. (1974). Familial renal agenesis and total dysplasia. American Journal of Diseases of Children, 128, 377-380.

Davidson, W. M., and Ross, Y. I. M. (1954). Bilateral absence of kidneys and related congenital anomalies. Journal of Pathology and Bacteriology, 68, 459-474.

Francois, J. (1969). Syndrome malformatif avec cryptophthalmos. Acta Geneticae Medicae et Gemellologiae, 18, 18-50.

Hack, M., Jaffe, J., Blankstein, J., Goodman, R. M., and Brish, M. (1974). Familial aggregation in bilateral renal agenesis. Clinical Genetics, 5, 173-177.

Kohn, G., and Borns, P. F. (1973). The association of bilateral and unilateral renal aplasia in the same family. Journal of Pediatrics, 83, 95-97.

Leck, I., Record, R. G., McKeown, T., and Edwards, J. H. (1968). The incidence of malformations in Birmingham, England, 1950-1959. Teratology, 1, 263-279.

Madisson, H. (1934). Uber das Fehlen beider Nieren. Zentralblatt für Allgemeine Pathologie und Pathologische Anatomie, 60, 1-8.

Mauer, S. M., Dobrin, R. S., and Vernier, R. L. (1974). Unilateral and bilateral renal agenesis in monoamniotic twins. Journal of Pediatrics, 84, 236-238.

Pashayan, H. M., Dowd, T., and Nigro, A. V. (1977). Bilateral absence of the kidneys and ureters. Three cases reported in one family. Journal of Medical Genetics, 14, 205-209.

Potter, E. L. (1965). Bilateral absence of ureter and kidney. Journal of Obstetrics and Gynaecology, 25, 3-12.

Potter, E. L. (1972). Extrinsic Abnormalities of Kidney in Normal and Abnormal Development of the Kidneys. Year Book Medical Publishers, Chicago.

Rogers, S. C., and Weatherall, J. A. C. (1976). Anencephalus, Spina Bifida and Congenital Hydrocephalus. OPCS Studies on Medical and Population Subjects, No. 32.

Schinzel, A., Homberger, C., and Sigrist, T. (1978). Bilateral renal agenesis in 2 male sibs born to consanguineous parents. Journal of Medical Genetics, 15, 314-316.

Winter, J. S. D., Kohn, G., Mellman, W. J., and Wagner, S. (1968). A familial syndrome of renal, genital and middle ear anomalies. Journal of Pediatrics, 72, 88-93.

Requests for reprints to Professor C. O. Carter, MRC Clinical Genetics Unit, Institute of Child Health, 30 Guilford Street, London WC1N 1EH. 


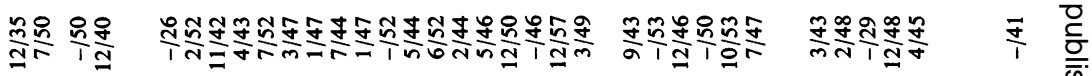

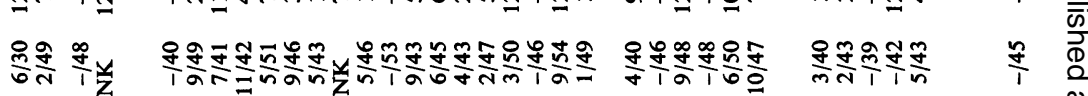
도옹용

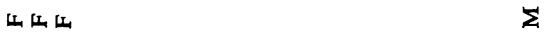

\section{西}

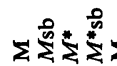

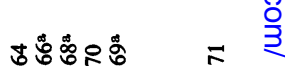

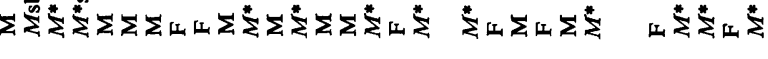

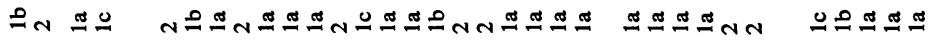




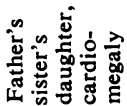

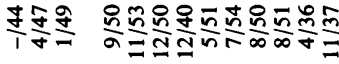

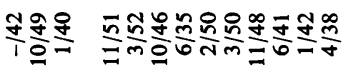

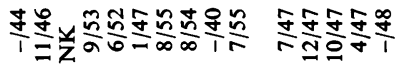

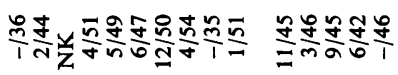

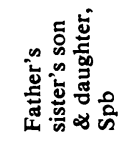

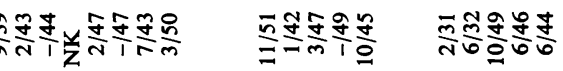

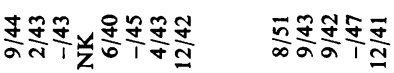

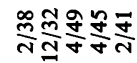

$$
\begin{aligned}
& \frac{N}{m} \frac{5}{\delta} \\
& \sum \Sigma
\end{aligned}
$$

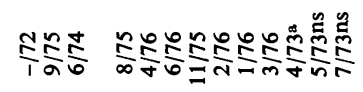

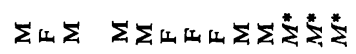

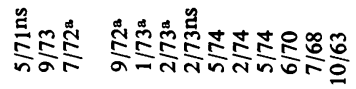

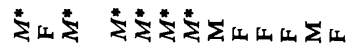

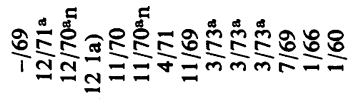

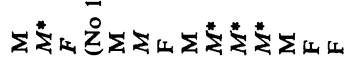

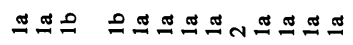

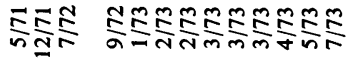

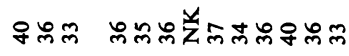

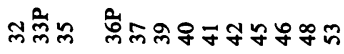

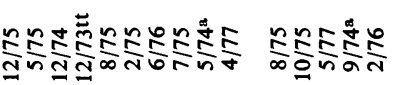

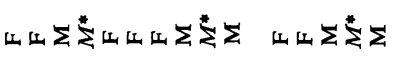

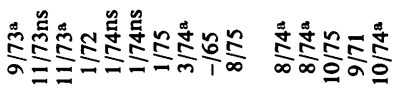

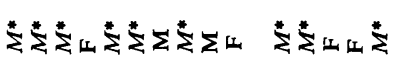

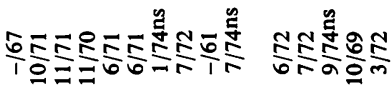

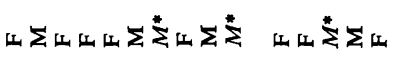

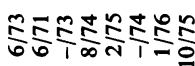

$\sum \omega \Sigma \Sigma \Sigma \Sigma 山$

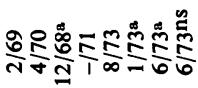

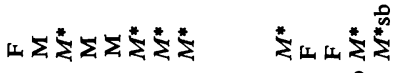

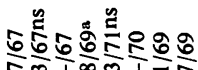

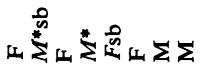

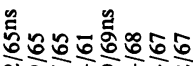

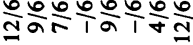

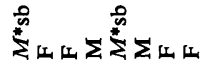

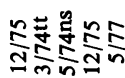

$\sum \sum \sum \Sigma$

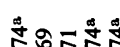
त드응

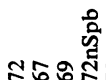
총으노ำ 山地芝山 ะํํํํำㄴำ 끄으응ㅇ $\sum \Sigma \Sigma 山$ 造

山以芝的的

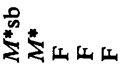
ํㅡㅇ주을응

山去安山 : กำํำำ 法艺山山

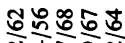
तTतू্

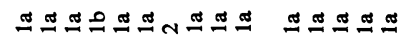

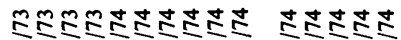

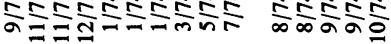

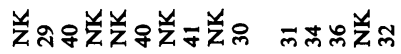

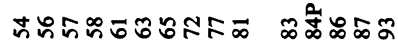

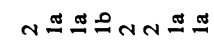
ำํำำก গ্工

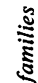

ำก็ก エே กักคั

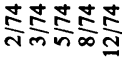

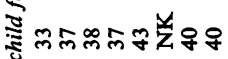

아으요유

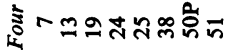

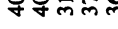
ธด์ณ๐

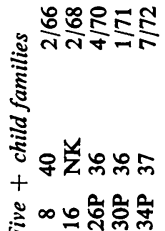




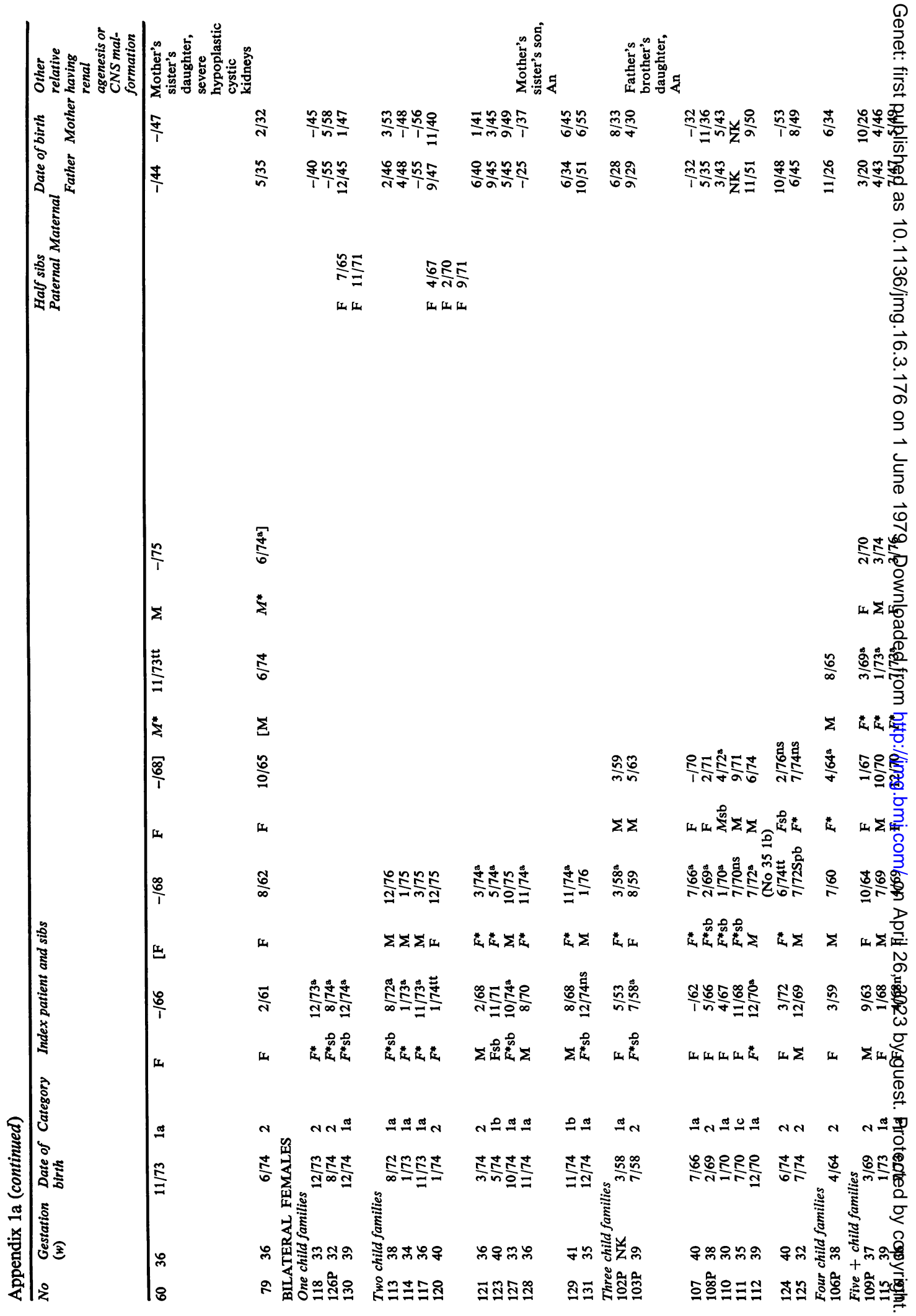




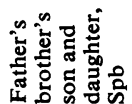

\begin{tabular}{|c|c|c|c|c|c|}
\hline$\frac{m}{y} \frac{n}{\infty}$ & 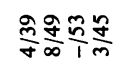 & 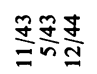 & $\frac{\bar{n}}{m}$ & $\stackrel{\cong}{\Xi}$ & $\frac{n}{n} \frac{i}{z}$ \\
\hline$\frac{\infty}{\infty}$ & 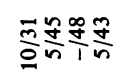 & $\sum_{\frac{\gamma}{\sigma}}^{\frac{n}{\pi}} \frac{\tilde{m}}{\infty}$ & 5 & $\stackrel{\bar{n}}{\beth}$ & $\frac{f}{a} \frac{\bar{n}}{n}$ \\
\hline
\end{tabular}

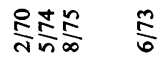

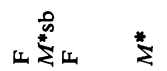

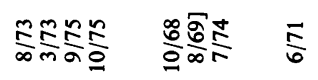

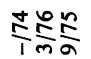

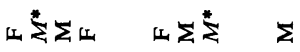

$\sum \sum \omega$

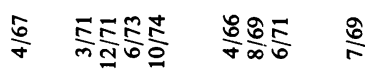

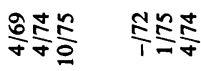

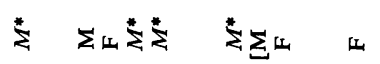

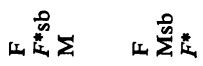

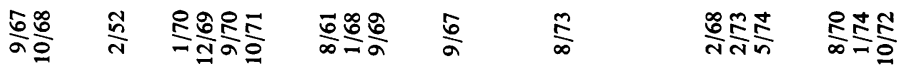

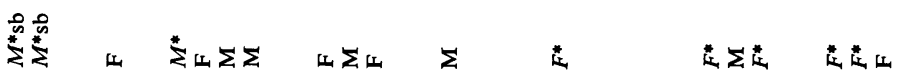

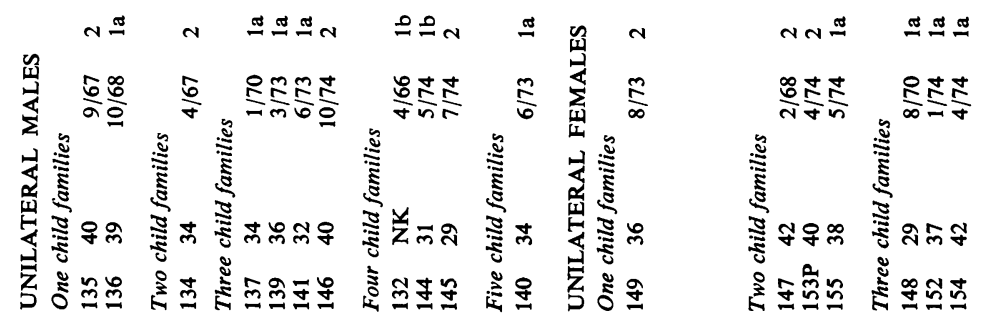


Appendix 1b No family information

\begin{tabular}{|c|c|c|c|c|}
\hline No & $\begin{array}{l}\text { Gestation } \\
(w)\end{array}$ & Category & Index patie & \\
\hline \multicolumn{5}{|c|}{ Bilateral male } \\
\hline $1 \mathbf{P}$ & 42 & $1 \mathrm{a}$ & $M^{*} \mathrm{sb}$ & $1 / 56^{\mathrm{a}}$ \\
\hline 2P & 30 & 2 & $M^{*} \mathrm{sb}$ & $3 / 56^{a}$ \\
\hline 4P & NK & $1 \mathrm{a}$ & $M^{*}$ & $12 / 58^{a}$ \\
\hline $5 P$ & NK & $1 \mathrm{a}$ & $M^{*}$ & $10 / 60^{\mathrm{a}}$ \\
\hline $6 P$ & 31 & $1 \mathrm{a}$ & $M^{*} \mathrm{sb}$ & $4 / 62^{a}$ \\
\hline 10 & 32 & $1 b$ & $M^{*}$ & $8 / 66^{a}$ \\
\hline 11 & 38 & $1 \mathrm{a}$ & $M^{*} \mathrm{sb}$ & $10 / 66$ ns \\
\hline 17 & 38 & $1 \mathbf{a}$ & $M^{*}$ & $2 / 68^{a}$ \\
\hline $18 \mathrm{P}$ & 40 & $1 \mathrm{a}$ & $M^{*}$ & $8 / 68^{a}$ \\
\hline 20 & 44 & $1 \mathrm{a}$ & $M^{*} \mathrm{sb}$ & $1 / 69^{a}$ \\
\hline 49 & 36 & $1 \mathrm{a}$ & $M^{*}$ & $6 / 73^{a}$ \\
\hline 52P & 34 & $1 \mathrm{a}$ & $M^{*} \mathrm{sb}$ & $7 / 73^{a}$ \\
\hline 62 & 37 & $1 \mathrm{a}$ & $M^{*}$ & $1 / 74^{\mathrm{a}}$ \\
\hline 64 & 34 & $1 \mathrm{a}$ & $M^{*}$ & $1 / 74^{\mathrm{a}}$ \\
\hline 68 & 37 & 2 & $M^{*}$ & $2 / 74^{a}$ \\
\hline 73 & 32 & la & $M^{*}$ & $4 / 74^{a}$ \\
\hline 80 & 42 & 2 & $M^{*}$ & $6 / 74^{a}$ \\
\hline 88 & 37 & 2 & $M^{*} \mathrm{sb}$ & $9 / 74 t$ \\
\hline 99 & NK & $1 \mathrm{a}$ & $M^{*}$ & $12 / 74 \mathrm{~ns}$ \\
\hline \multicolumn{5}{|c|}{ Bilateral female } \\
\hline 104P & NK & 2 & $F^{*}$ & $5 / 62^{a}$ \\
\hline $105 P$ & 41 & 2 & $F^{*}$ & $3 / 64^{a}$ \\
\hline 119 & 32 & $1 b$ & $F^{*}$ & $1 / 74 \mathrm{tt}$ \\
\hline 122 & 35 & $1 \mathrm{a}$ & $F^{*} \mathrm{sb}$ & $4 / 74^{a}$ \\
\hline \multicolumn{5}{|c|}{ Unilateral male } \\
\hline 133 & 38 & $1 b$ & $M^{*}$ & $2 / 67$ \\
\hline 138 & 35 & $1 \mathrm{a}$ & $M^{*}$ & $1 / 73$ \\
\hline 142 & 36 & $1 \mathrm{a}$ & $M^{*}$ & $6 / 73$ \\
\hline 143 & 31 & $1 \mathrm{a}$ & $M^{*}$ & $10 / 73$ \\
\hline \multicolumn{5}{|c|}{ Unilateral female } \\
\hline 150 & 36 & $1 \mathrm{a}$ & $F^{*}$ & $8 / 73$ \\
\hline 151 & 34 & 2 & $F^{*}$ & $11 / 73$ \\
\hline
\end{tabular}

Italicised, affected; *, index patients; sb, stillbirth; ns, no statement on ureters; tt, elements of 2 ureters present; a, ureters stated absent.

Appendix 2 Other malformation in category 2 index patients

\begin{tabular}{lrl}
\hline Cardiovascular system & & \\
Bilateral male & 2 & ASD VSD \\
& 7 & Transposition of great vessels \\
& 15 & ASD VSD \\
& 22 & ASD PS \\
& 25 & Single ventricle, no septum \\
& 76 & ASD \\
& 80 & VSD \\
Bilateral female & 101 & VSD LSVC \\
& 105 & ASD LSVC \\
& 109 & VSD \\
& 120 & PS \\
Unilateral male & 126 & Common AV canal \\
& 135 & ASD \\
Unilateral female & 155 & Situs inversus \\
Gastrointestinal system & Cardiomegaly \\
Bilateral male & $22 *$ & TOF \\
& 27 & TOF \\
& 59 & Oesophageal atresia \\
& 65 & TOF \\
& 79 & TOF \\
& 82 & Oesophageal atresia \\
& 88 & TOF \\
& $101^{*}$ & TOF
\end{tabular}

\section{Appendix 2-continued}

\begin{tabular}{|c|c|c|}
\hline \multirow[t]{2}{*}{ Bilateral female } & 108 & Pyloric hypertrophy \\
\hline & 124 & Tracheal stenosis \\
\hline Unilateral female & 149 & Duodenal atresia, omphalocele \\
\hline \multicolumn{3}{|c|}{ Central nervous system } \\
\hline \multirow[t]{2}{*}{ Bilateral male } & 26 & Myelomeningocele \\
\hline & 31 & Meningoencephalocele \\
\hline \multirow[t]{4}{*}{ Bilateral female } & 103 & Meningomyelocele \\
\hline & 106 & Meningomyelocele, microgyria \\
\hline & $108^{*}$ & Meningomyelocele \\
\hline & 125 & Meningomyelocele \\
\hline & 146 & Spina bifida, posterior sacrum abse \\
\hline Unilateral fe & 152 & Meningocele \\
\hline
\end{tabular}

Eyes

Bilateral male $\quad 8 \quad$ R. microphthalmia

$25^{*}$ One eye absent

34 Bilateral cataracts

38 Bilateral cataracts

85 R. cataract

$\begin{array}{lll}\text { Bilateral female } & 100 & \begin{array}{l}\text { Microphthalmia } \\ \text { Cataract }\end{array}\end{array}$

Skull and face

Bilateral male

8* Microcephaly

42 Cleft palate

59* Harelip

Bilateral female $104^{*}$ Microcephaly

126* Cleft larynx

$\begin{array}{lll} & 126^{*} & \text { Cleft larynx } \\ \text { Unilateral female } & 147 & \text { Cleft palate }\end{array}$

Hands

Bilateral female

42* Deformity fingers

59* Deformity elbows

68 Left polysyndactyly

76* Fused and missing phalanges, elbows displaced

Vertebral column

Bilateral male

Bilateral female $120^{*}$ Klippel Feil

Brain

Bilateral male 24* Microgyria

Bilateral female $106^{*}$ Microgyria

118 Microgyria

\begin{tabular}{lll} 
Unilateral male & 118 & Microgyria \\
\hline
\end{tabular}

*More than 1 other malformation.

Appendix 3 Anomaly in other kidney in 24 patients with unilateral agenesis

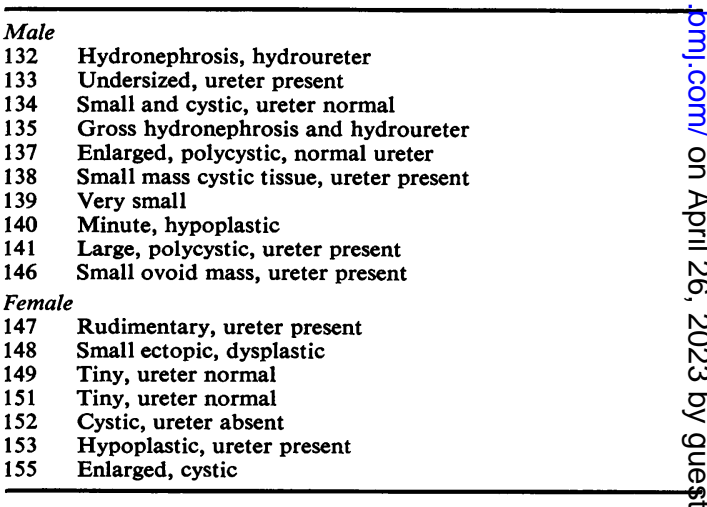

